\title{
The Role of Anchoring Bias on Economic and Financial Knowledge: A Study Based on Business Graduates
}

\author{
Dr. KALIMULLAH BHAT \\ Assistant Professor, Department of Banking and Finance, \\ University of Kotli AJ \& K. \\ Dr. GHULAM NABI \\ Assistant Professor, Department of Business Administration, \\ University of Kotli AJ \& K. \\ Email: dr.ghulamnabi@uokajk.edu.pk \\ Ms. NAVEEDA ZEB \\ Assistant Professor, Department of Business Administration, \\ University of Kotli AJ \& K.
}

\begin{abstract}
The purpose of this study is to determine the role of anchoring bias in the economic and financial information. An experiment involving the business students is carried out by providing them information about recent economic and financial anchors about stock market, index returns, inflation and exchange rates in groups where one groups is exposed to some relevant anchors. In the first group, which is the "control group" the participants were given no relevant information and were asked to give their best estimate for all the respective indicators. In the second group the "anchoring group" participants were asked the same questions but are provided indicator anchors to deduce their anchoring estimates, for instance the current value of KSE-100 index is provided, and the respondents were asked to predict the current value of KSE-30 index. The results show that there is significant degree of anchoring bias for each of the questions and it is higher for males as compare to females. Similarly, the respondents when exposed to relevant anchors show significant anchoring bias than for irrelevant anchors.
\end{abstract}

Keywords: Anchoring Bias, Relevant Anchoring, Irrelevant Anchoring, Perceived Relevance, Financial Indicators.

\section{Introduction}

The discipline of behavior finance provides solution to cognitive errors and anomalies, which leads to irrationality in investors and markets. Behavior finance deals with the problem that how the individuals deviate from the rational behavior Kudryavtsev and Cohen (2010) noted that analysts play an important role in financial markets as their earnings forecasts are used for market expectations and anchoring is a phenomenon by which people make an arbitrary value and then adjust their target towards it.

Anchoring and adjustment is a cognitive bias, which has two approaches, relevant anchors, and irrelevant anchors. Researchers most come with findings that relevant anchors have more affect on decision making than irrelevant anchors. Relevant anchors are those figures or values, which are relevant to the field where a person want to make decision-making. For instance, if a person is provided with the return of S\&P 500 and is asked to deduce the return of KSE 100 index; we can say this is relevant anchor. On the other hand, if a 
person is given the information of sugar price and is asked to estimate the price of KSE 30 index it is called irrelevant anchors. There can be impact of both relevant and irrelevant anchoring on economic and financial knowledge, which can lead to wrong decision making.

Tversky and Kahneman (1974) in their study proposed the anchoring bias by arguing that it is a process by which people make their estimates towards a certain target, which are insufficient, and this shows the presence of bias called anchoring. Besides the work of Tversky and Khaneman (1974), many other studies have measured the anchoring effects and the results are robust. For instance, Plous (1989), Chapman and Johnson (1994), and Northcraft \& Neale (1987). The phenomenon of anchoring bias is critical as Northcraft and Neale (1987) in their study noted that anchoring bias affects both experts as well as students. Strack and Mussweiler (1997) noted that anchoring bias is easy to measure but difficult to explain. Economic rationale theory suggests that human nature is risk averse and sticking to specific value can lead an individual towards wrong decision-making. A wide range of factors can lead to anchoring bias, previous studies shows that the personality is also correlated with the anchoring bias, Eroglu and Crozxton (2010) argued that people with high degree of agreeableness and consciousness are affected by anchoring bias. Similarly, McElroy and Dowd (2007) noted that openness also affects the anchoring bias and that people with high degree of openness are susceptible to anchoring bias.

\section{Objectives}

- To investigate the impact of anchoring bias in financial and economic information.

- To determine the extent of perceived relevance in anchoring bias.

\section{Research Questions}

What is the impact of anchoring bias in financial and economic information? How perceived relevance is related to anchoring bias?

After going through literature, it is found that the relevance illusion and anchoring in economic and financial knowledge has not been investigated in the context of Pakistan. So, on the time and geographical basis there is need to investigate it, which will be beneficial for both practitioners as well as academies. For an academic perspective it can help students to understand the impact of anchoring and adjustment bias on the economic information and it can also guide the practitioners in optimal decision making.

The remainder of the paper is organized as follows: The next section includes a review of the related literature. Section 3 describes the data and methods used in the analysis. Empirical findings are reported in Section 4, and conclusions are discussed in the final section.

\section{Literature Review}

There are several systematic biases in human decisions. Anchoring adjustments bias is one of them, which make human judgments inefficient. Anchoring is a term in psychology generally described as the person's behavior to rely on some specific information while making decisions. While making investment decisions we may fall prey in anchoring bias, which lead us to inefficient investment decisions. Tversky and Kahneman (1974) defined that "anchoring and adjustment is a psychological heuristic that influences the way people intuitively assess probabilities". In an experiment Tversky and Kahneman (1974) examined the impact of anchoring on the estimates of respondents. The anchoring bias affects a person by creating an anchor in his mind regarding an investment or decision and then tends to adjust towards that reference point. This cognitive bias lead to distortion in optimal decision making, anchoring affects decision making 
of the individuals in an important economic setting and that level of anchoring grows as the gap between rational value and market price increases.

Arnott (1998) in his study noted that the individual's adjustment from their initial position is insufficient, he asked the respondents to estimate the length of the river with by providing an anchor value of over 500 miles to one group and under 5000 miles to the other. The estimate of first was 1000 and the second group was 3000 miles, while the correct answer was 2300 miles. This shows that anchor estimates are determined according to the reference point provided which leads to insufficient decisions. Jacowitz and Kahneman (1995) asked the students some general questions as (length of Mississippi and height of Everest) and noted that participants with who were given high anchors answered their estimates as high anchors than those with low anchors. Northcraft and Neale (1987) noted that experts are more likely to show anchoring bias in their decision making than students even if it is related to their household activities. Karaa (2011) noted that anchoring bias could lead managers to make financing decision with low returns, which ultimately affects the shareholders wealth. Beggs \& Graddy (2009) noted that anchoring does influence the persons in their estimates and people tend to make anchors regarding their previous experience.

Critcher \& Gilovich (2008) studied basic and standard anchoring and noted that people are influenced by basic anchoring when making the decisions. Kudryavtsev and Cohen (2010) used the basic anchoring approach argued that anchoring bias becomes stronger when the people are aware of the situations/questions i.e., when they have some prior information. Critcher et al (2008) noted that the arbitrary reference point influences the anchor and the adjustment process and provide a reasonable estimate anchor, the direction of adjustment acts as an attractor which can be distal or proximal during the adjustment process.

Barbosa \& Fayolle (2007) claimed that cognitive heuristics cannot be disassociated from the situational contexts and in case of risk perception the anchoring effects are stronger than the availability effects. Einhorn and Hogarth (1987) argued that a common example of anchoring bias in corporate sector is to forecast the next year sales by taking the sales figure of last year with a 5\% estimate. Mussweiler \& Strack (1999) described the anchoring phenomena by one of its main characteristics by using what appears most efficient strategy for a comparative task distorts the subsequent absolute judgment. Sometimes people make their decisions based on false information. Qu and Luo (2008) noticed that impact of false information produces a judgmental contamination. There are some factors, which play a role on anchored judgments.

Furnham and Boo (2010) examined that individual differences and situational factors play a small role on anchored judgements. It is contributed to the literature that there is joint effect of anchoring and framing bias on human decisions. Wu and Cheng (2011) suggested that comparison of message framing and anchor point enhances the effects of information presentation on consumer responses regarding product attitudes, purchase intention and willingness to pay. Durability of anchoring effects on decision-making is also investigated. Mussweiler (2001) noticed anchoring effects are remarkably durable. They reliably influence the judgment target to the anchor.

Kudryavtsev and Cohen (2010) noticed that when an investor considers purchasing a stock and respectively tries to forecast its future returns, the less fundamental information he has about the issuing company, the more he will be affected by any anchors to which he or she is currently exposed. Mussweiler and Strack (1999) suggested that to further our understanding about human judgment under uncertainty, it might be fruitful to closely examine those factors that determine uncertainty in the first place.

Previous research about anchoring bias has explored that there are two types of anchoring, standard anchoring, and basic anchoring. Wilson et al (1996) in their study noted that basic anchoring occurs when people pay sufficient attention to the anchor value and that the basic anchoring effects have less influence on individuals with relevant knowledge about the situations. Englich (2008) in his study asked the respondents to estimate the average price of German cars by providing information about relevant and 
irrelevant anchoring and noted that relevant information decreases the effect of anchoring and argued there are two types of anchoring effects, when a person compares the anchor with the target then basic anchoring occurs and when accessibility of anchor about the target is increased then it is standard anchoring. Critcher \& Gilovich (2008) studied basic and standard anchoring and noted that people are more influenced by basic anchoring when making the decisions.

Kudryavtsev \& Cohen (2010) used the basic anchoring approach and argued that anchoring bias becomes stronger when the people are aware of the situations/questions i.e., when they have some prior information. Brewer and Chapman (2002) in their study noted that basic anchoring differs from standard anchoring in a sense that it does not compare anchor numbers with some unknown quantity and that this presentation of number to the individuals create bias in their judgments. In this study basic anchoring approach will be used as adopted from the work of Kudryavtsev and Cohen (2010) where the anchoring results are produced by increasing the accessibility of anchor value.

\section{Hypothesis 1}

H0: There is no anchoring bias for question " $\mathrm{n}$ ".

$\mathrm{H} 1$ : There is positive anchoring bias for question " $n$ ".

\section{Hypothesis 2}

H0: There is no anchoring bias for respective sample/sub sample.

H1: There is positive anchoring bias for respective sample/sub sample.

\section{Hypothesis 3}

H0: There is similar degree of anchoring bias for both categories of questions.

H1: There is stronger anchoring bias fro question with relevant anchors than for the questions with irrelevant anchors.

\section{Research Methodology}

\section{Research Design}

In the first group, which is the "control group" the participants were given no relevant information and were asked to give their best estimate for all the respective indicators. In the second group the "anchoring group" participants are asked the same questions but are provided indicator anchors to deduce their anchoring estimates. e. g, the current value of KSE-100 index is provided, and the respondents is asked to predict the current value of KSE-30 index. Similarly, the question for irrelevant anchoring is about the manufacturing production in Pakistan and respondents will be asked about the value of KMI-30 index. We expect that the results of anchoring group will be closer to the anchor indicators than the control group.

\section{Sample}

An experiment involving 60 students at International Islamic University has been conducted, where the participants were requested to recall some economic and financial indicators of Pakistan economy generally and particularly Karachi Stock Exchange. The MBA students were the respondents, and the experiment was conducted on two groups. As, study is experimental in nature, and considering the time and cost limitations the sample is comprised of only 60 students. 


\section{Measurement}

In the previous studies the impact of anchoring bias is measured by two approaches, the basic anchoring, Kudravystev and Cohen (2010) or standard anchoring, Tversky and Kahneman (1974). To calculate the anchoring measures, the method consistent with the study of Jacowitz and Kahneman (1995) and Kudryastev and Cohen (2010) is used. The anchoring measure for each question in group A will be calculated as

$$
A n i=1-\left[R A^{i}-\operatorname{In}\right] / D C n
$$

Where: Ani-Anchoring (bias) measure for question $n$ and person $i, R A^{i}-$ actual answer of question $\mathrm{n}$ given by participant $i$ from group A, $I n$ - indicator of anchor for question n, $D C n$ - mean deviation for the anchor for the question $\mathrm{n}$, in group $\mathrm{C}$, which is calculated by

$$
D C n=[R C n-\operatorname{In}] / N C
$$

Where $R C n$ - actual answer to question $\mathrm{n}$ given by participant $\mathrm{j}$ from Group $\mathrm{C}, N C$-number of participants in-Group C, Participants in group A who are not influenced by the anchoring bias should provide the value of $R A i$ as they would have provided if they were not aware of anchoring indicator i.e., if they were in group $\mathrm{C}$ then their response ( $R A i$ and $R C n$ ) should be same, and thus the value of An should be equal to zero. As the equation 1 and 2 shows that absolute individuals are used, instead of average deviation of actual answers form the anchors. The benefit of absolute individual is that it helps to determine that how close the answer is with respect to the anchor, which is not possible by using the average method. This could be because $R a i$ and $R C n$ could be equal on average. To calculate mean anchoring measures, first the anchoring measures for each question will be calculated.

$$
A Q n=E A n i / N A
$$

Where $A Q n$ is mean anchoring measure for question $n, N A$ is the number of participants in Group A which is 30 participants.

Similarly, for each participant i from group 'A' APi is calculated

$$
A P i=E A n i / N Q
$$

Here $(A P i)$ is the personal anchoring measure for each participant and NQ is the number of questions, which are 15 .

\section{Results}

The summary statistics and the significance level calculated for all the participants of their anchoring measures (An) and it is shown below. The table 1 shows the results for our first hypothesis. Results shows that anchoring bias measure for the entire questions is positive and significant, (12 of the questions are significant at $1 \%$ level), which shows the presence of strong anchoring bias (t-statistic values is $A Q>0)$. Thus, we reject Ho and accept $\mathrm{H} 1$ that the participants exhibit anchoring bias for the respective questions n. The results how that there is presence of anchoring bias for all the questions asked to the respondents. This result is line with the findings of Wilson et al. (1996), Kudryavtsev and Cohen (2010) who also found strong positive anchoring bias for the experiment questions. 


\begin{tabular}{|c|c|c|c|c|c|c|c|}
\hline $\begin{array}{ll}\mathrm{B} & \mathbf{n} \\
\mathrm{R} & \mathrm{I}\end{array}$ & $\begin{array}{l}\text { w.irmb } \\
\text { ernation }\end{array}$ & $\frac{\text { journal.com }}{\text { al Review of M }}$ & anagement and & 3usiness Resea & & \multicolumn{2}{|c|}{$\begin{array}{r}\text { March } 2021 \\
\text { Vol. } 10 \text { Issue.1 } \\
\end{array}$} \\
\hline \multicolumn{8}{|c|}{$\begin{array}{c}\text { Table 1: Anchoring Measure statistics for questions } \\
\text { Personal Anchoring measure }(\boldsymbol{A P})\end{array}$} \\
\hline $\begin{array}{l}\text { Question } \\
\text { No. }\end{array}$ & Mean & Median & $\begin{array}{l}\text { Standard } \\
\text { Deviation }\end{array}$ & Maximum & Minimum & $\begin{array}{c}\text { AQ>0 } \\
\text { t-statistic }\end{array}$ & $\begin{array}{c}\text { P- } \\
\text { value }\end{array}$ \\
\hline 1 & 0.312 & 0.192 & 0.306 & 1.080 & 0.239 & 5.58 & .000 \\
\hline 2 & 0.252 & 0.254 & 0.012 & 0.265 & 0.018 & 112.64 & .000 \\
\hline 3 & 0.297 & 0.297 & 0.001 & 0.302 & 0.029 & $1.365 \mathrm{E} 3$ & .000 \\
\hline 4 & 0.009 & 0.094 & 0.0001 & 0.998 & 0.093 & 266.82 & .000 \\
\hline 5 & 0.279 & 0.286 & 0.037 & 0.291 & .0823 & 41.07 & .000 \\
\hline 6 & 0.037 & 0.037 & 0.0003 & 3.770 & 0.036 & 652.48 & .000 \\
\hline 7 & 0.331 & 0.334 & 0.008 & 3.375 & 0.301 & 212.63 & .000 \\
\hline 8 & 0.307 & 0.311 & 0.012 & 3.147 & 0.264 & 136.64 & .000 \\
\hline 9 & 0.322 & 0.347 & 0.060 & 3.549 & 0.109 & 28.97 & .000 \\
\hline 10 & 0.112 & 0.050 & 0.403 & 2.216 & 0.106 & 1.53 & 137 \\
\hline 11 & 0.291 & 0.290 & 0.0009 & 2.934 & 0.290 & $1.688 \mathrm{E} 3$ & .000 \\
\hline 12 & 0.016 & 0.032 & 0.038 & 1.788 & 0.018 & 2.34 & .026 \\
\hline 13 & 0.009 & 0.006 & 0.013 & 6.636 & 0.0200 & 3.89 & .001 \\
\hline 14 & 0.031 & 0.071 & 0.085 & 0.437 & 0.027 & 2.04 & .050 \\
\hline
\end{tabular}

Anchoring Bias by participants and categories of participants

The anchoring bias measure for the total sample and the sub sample with respect to the gender, age and previous education is calculated. The mean for $A P$-personal anchoring measure for all the questions is calculated and is categorized as gender (male 18 respondents and female 12 respondents), age group (less than 22,10 respondents and 22-25,20 respondents) and previous education (B. Com, 9 participants and BBA, 21 participants). Table 2 shows the summary statistics and significance for the hypothesis for personal anchoring measures of each of the participants.

Table 2: Anchoring Bias by participants and categories of participants

\begin{tabular}{|c|c|c|c|c|c|c|c|}
\hline 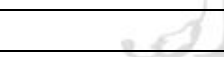 & $\sqrt{x}$ & \multicolumn{4}{|c|}{ Personal Anchoring Measure AP } & \multicolumn{2}{|c|}{ 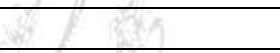 } \\
\hline $\begin{array}{l}\text { Categories of } \\
\text { Anchor }\end{array}$ & Mean & Median & $\begin{array}{l}\text { Standard } \\
\text { Deviation }\end{array}$ & Maximum & Minimum & $\begin{array}{l}\text { Mean } \\
\text { AP>0 } \\
\text { t- } \\
\text { statistic }\end{array}$ & $\begin{array}{l}P \\
\text { value }\end{array}$ \\
\hline $\begin{array}{c}\text { Total Sample } \\
(30)\end{array}$ & 0.389 & 0.559 & 0.280 & 0.678 & 0.340 & 5.381 & $(.000)$ \\
\hline $\begin{array}{l}\text { Gender } \\
\text { Male (18) }\end{array}$ & 0.233 & 0.329 & 0.042 & 0.404 & 0.099 & 5.510 & $(.000)$ \\
\hline Female(12) & 0.156 & 0.229 & 0.121 & 0.287 & 0.121 & 4.997 & $(.000)$ \\
\hline Age & & & & & & & \\
\hline Age $<22 \quad$ (10) & 0.128 & 0.173 & 0.090 & 0.260 & 0.112 & 5.494 & $(.000)$ \\
\hline Age22-25 (20) & 0.261 & 0.384 & 0.201 & 0.475 & 0.452 & 5.029 & $(.000)$ \\
\hline Previous Quali & fication & & & & & & \\
\hline B.Com (9) & 0.103 & 0.144 & 0.08 & & & 4.858 & $(.000)$ \\
\hline$B B A(21)$ & 4.219 & 5.645 & 2.99 & 7.477 & 0.580 & 5.461 & $(.000)$ \\
\hline
\end{tabular}

The table shows that results are significant at $1 \%$ confidence level for all the samples and sub samples. Thus, the result rejects Ho and accepts $\mathrm{H} 1$ that there is anchoring bias for all the participants. Also, the anchoring bias measure is stronger in males as compare to females. Similarly, respondents with previous education BBA are more influenced by the anchoring indicators as compare to those with B.com as previous education. The age group factor also has slight effect on the degree of bias. 
Effect of anchor's relevance on the degree of anchoring bias

Table 3: Effect of anchor's relevance on the degree of anchoring bias

\begin{tabular}{|c|c|c|c|c|c|c|c|}
\hline \multicolumn{8}{|c|}{ Personal Anchoring Measure AQ } \\
\hline $\begin{array}{l}\text { Categories of } \\
\text { Anchor }\end{array}$ & Mean & Median & $\begin{array}{l}\text { Standard } \\
\text { Deviation }\end{array}$ & Maximum & Minimum & t-statistic & $\begin{array}{l}\text { P- } \\
\text { value }\end{array}$ \\
\hline Sample(15) & 0.1967 & 0.279 & 0.139 & 0.339 & 0.009 & 5.397 & 0.001 \\
\hline Relevant 8) & 0.300 & 0.307 & 0.027 & 0.331 & 0.252 & 5.007 & 0.002 \\
\hline Irrelevant (7) & 0.119 & 0.037 & 0.138 & 0.339 & 0.009 & 2.731 & 0.034 \\
\hline
\end{tabular}

The table 3 shows that mean values of personal anchoring measure-AQ for the relevant anchoring is greater than those for irrelevant anchors. The mean value for relevant anchors question is .3060 as compare to 0.119 for irrelevant anchors. Thus we accept our $\mathrm{H} 1$ that respondents will exhibit strong anchoring bias for questions with relevant anchors. the p-value for relevant anchor is significant at confidence level of 5\%. This result is also consistent with the study of Kudryastev and Cohen (2010) as they also found strong anchoring bias for questions with relevant anchors.

\section{Discussion}

The empirical evidence suggests that male participants more influenced by the anchors as compare to female. This finding is in contrast the study of Kudravstev and Cohen (2010) Also the respondents are more influenced by the relevant anchors than irrelevant anchors. This paper analyzed the role of anchoring bias in perceived economic and financial information and the effect of relevant anchoring to the degree of bias by providing experiment questions to the respondents familiar with the economic and financial indicators. The results show that there is strong anchoring bias present for all the questions answered by the respondents and the degree of bias is higher for male and persons with previous education as BBA. Similarly, the effect of anchoring is increased when the participants are asked questions with some relevant anchors.

\section{Recommendations}

Our finding shows that participants exhibit strong anchoring bias as they are anchored by the average return of index and sticks. Individuals who exhibit anchoring bias can make mistakes in their estimation and forecasting. Generally, the individuals are influenced by the target anchors like the average annual return of index and long-term return of stocks but usually the stocks deviate from their long-term average. The finding of this study may have some useful implications for managers involved in forecasting and decisionmaking regarding the financial markets.

\section{Conclusion}

In this study we investigated the role of anchoring bias in economic and financial knowledge of business graduates. An experiment involving the business students is carried out by providing them information about recent economic and financial anchors about stock market, index returns, inflation and exchange rates in groups where one groups is exposed to some relevant anchors. In the first group, which is the "control group" the participants were given no relevant information and were asked to give their best 
estimate for all the respective indicators. In the second group the "anchoring group" participants were asked the same questions but are provided indicator anchors to deduce their anchoring estimates, for instance, the current value of KSE-100 index is provided, and the respondents were asked to predict the current value of KSE-30 index. To calculate the anchoring measures, the method consistent with the study of Jacowitz and Kahneman (1995) and Kudryastev and Cohen (2010) is used in the study. The results show that there is significant degree of anchoring bias for each of the questions and it is higher for males as compare to females. Similarly, the respondents when exposed to relevant anchors show significant anchoring bias than for irrelevant anchors.

\section{References}

Arnott, R. (1998). Economic theory and the spatial mismatch hypothesis. Urban studies, 35(7), 1171-1185.

Brewer, N. T., \& Chapman, G. B. (2002). The fragile basic anchoring effect. Journal of Behavioral Decision Making, 15(1), 65-77.

Beggs, A., \& Graddy, K. (2009). Anchoring effects: Evidence from art auctions. American Economic Review, 99(3), 1027-39.

Barbosa, S. D., \& Fayolle, A. Where is the risk? Availability, anchoring, and framing effects on entrepreneurial risk taking. Frontiers of Entrepreneurship Research, 27(6). 1-1

Chapman, G. B., \& Johnson, E. J. (1994). The limits of anchoring. Journal of Behavioral Decision Making, 7(4), 223-242.

Critcher, C. R., \& Gilovich, T. (2008). Incidental environmental anchors. Journal of Behavioral Decision Making, 21(3), 241-251.

Eroglu, C., \& Croxton, K. L. (2010). Biases in judgmental adjustments of statistical forecasts: The role of individual differences. International Journal of Forecasting, 26(1), 116-133.

Englich, B. (2008). When knowledge matters - differential effects of available knowledge in standard and basic anchoring tasks. European Journal of Social Psychology, 38(5), 896-904.

Einhorn, H. J., \& Hogarth, R. M. (1981). Behavioral decision theory: Processes of judgement and choice. Annual review of psychology, 32(1), 53-88.

Furnham, A., \& Boo, H. C. (2011). A literature review of the anchoring effect. The journal of socioeconomics, 40(1), 35-42.

Jacowitz, K. E., \& Kahneman, D. (1995). Measures of anchoring in estimation tasks. Personality and Social Psychology Bulletin, 2l(11), 1161-1166.

Kudryavtsev, A., \& Cohen, G. (2010). Anchoring and pre-existing knowledge in economic and financial settings. American Journal of Social and Management Sciences, 1(2), 164-180.

Kudryavtsev, A., \& Cohen, G. (2010). Illusion of relevance: Anchoring in economic and financial knowledge. International Journal of Economics and Research, 1, 86-101.

Karaa, I. E. (2011). Impact of Anchoring Bias on Corporate Profits and Shareholders Wealth. International Journal of Economics and Finance Studies, 3(2), 105-115.

McElroy, T., \& Dowd, K. (2007). Susceptibility to anchoring effects: How openness-to-experience influences responses to anchoring cues. Judgment and Decision making, 2(1), 48.

Mussweiler, T. (2001). The durability of anchoring effects. European Journal of Social Psychology, 31(4), 431-442.

Mussweiler, T., \& Strack, F. (1999). Hypothesis-consistent testing and semantic priming in the anchoring paradigm: A selective accessibility model. Journal of Experimental Social Psychology, 35(2), 136-164.

Northcraft, G. B., \& Neale, M. A. (1987). Experts, amateurs, and real estate: An anchoring-and-adjustment perspective on property pricing decisions. Organizational behavior and human decision processes, 39(1), 84-97.

Plous, S. (1989). Thinking the unthinkable: The effects of anchoring on likelihood estimates of nuclear war 1. Journal of Applied Social Psychology, 19(1), 67-91.

Qu, C., Wang, J., \& Luo, Y. (2008). Inconspicuous anchoring effects generated by false information. Progress in Natural Science, 18(11), 1375-1382. 
Strack, F., \& Mussweiler, T. (1997). Explaining the enigmatic anchoring effect: Mechanisms of selective accessibility. Journal of personality and social psychology, 73(3), 437.

Tversky, A., \& Kahneman, D. (1974). Judgment under uncertainty: Heuristics and biases. science, 185(4157), 1124-1131.

Wu, C. S., \& Cheng, F. F. (2011). The joint effect of framing and anchoring on internet buyers' decisionmaking. Electronic Commerce Research and Applications, 10(3), 358-368.

Wilson, T. D., Houston, C. E., Etling, K. M., \& Brekke, N. (1996). A new look at anchoring effects: basic anchoring and its antecedents. Journal of Experimental Psychology: General, 125(4), 387.

\section{Research questionnaire (Group A)}

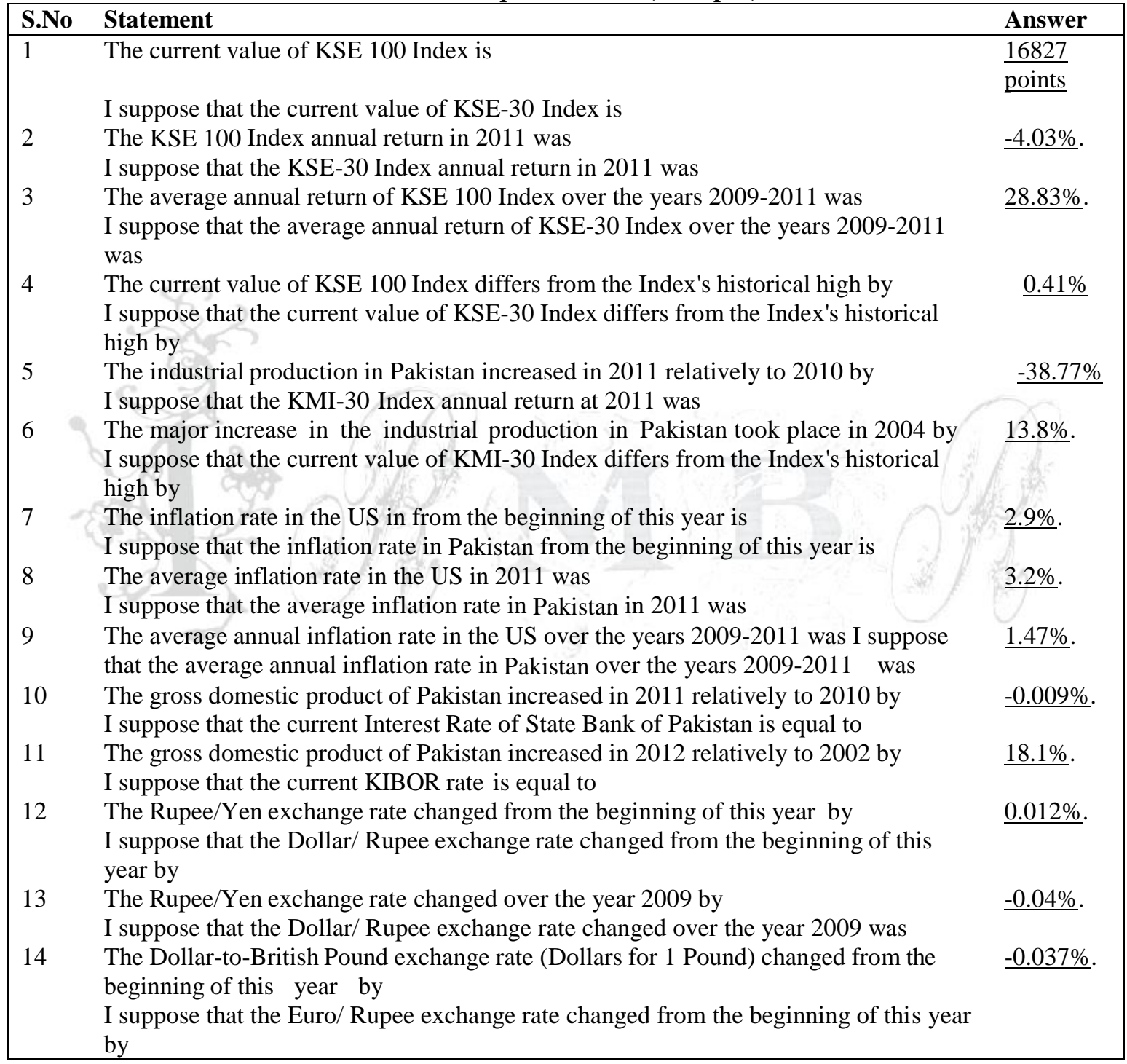

